\title{
Errata
}

\section{Measuring disease severity in Duchenne and Becker muscular dystrophy}

\author{
Melinda F. Davis, Katalin Scherer, \\ Timothy M. Miller, F. John Meaney \\ University of Arizona
}

Reports an error in Davis et al. (2010). The functional motor scale used in Davis et al. (2010) was the EK (Egen Klassifikation) Scale, rather than the Amyotrophic Lateral Sclerosis Functional Rating Scale (Steffensen et al., 2002; Cedarbaum \& Stambler, 1997). Both scales are 10-item, diseasespecific measures that assess mobility and respiratory function in individuals with progressive muscle weakness. This error does not change the conclusions.

\section{References}

Cedarbaum JM, Stambler N. (1997). Performance of the Amyotrophic Lateral Sclerosis Functional Rating Scale (ALSFRS) in multicenter clinical trials. Journal of the Neurological Sciences. 152(Suppl. 1):S1-9.

Davis MF, Scherer, K, Miller TM, Meaney FJ. (2010). Measuring disease severity in Duchenne and Becker muscular dystrophy. Methods and Measurement in the Social Sciences. 1:8-18.

Steffensen BF, Lyager S, Werge B, Rahbek J, Mattsson E. (2002). Physical capacity in non-ambulatory people with Duchenne muscular dystrophy or spinal muscular atrophy: a longitudinal study. Developmental Medicine \& Child Neurology. 44:623-632. 